\title{
Effect of Chloride Diffusion on Corrosion Behavior of 304SS Steel in Simulated Concrete Solution under Carbonation Condition
}

\author{
Senlin $\mathrm{Li}^{1}$, Weihang $\mathrm{Miao}^{2}, \mathrm{Ye} \mathrm{Wu}^{1}$, Lupeng Liu ${ }^{2}$, Zhiming Gao ${ }^{2, *}$ \\ ${ }^{1}$ Nanjing water conservancy research institute, Nanjing, Jiangsu 20029; \\ ${ }^{2}$ Tianjin Key Laboratory of Composite \& Functional Materials, School of Materials Science and \\ Engineering, Tianjin University, Tianjin, 300350, China \\ *E-mail: gaozhiming@tju.edu.cn
}

Received: 18 May 2021 / Accepted: 7 July 2021 / Published: 10 August 2021

\begin{abstract}
The corrosion behavior of 304 stainless steel reinforced concrete in the simulated seawater environment is studied using the ion diffusion method to accelerate the carbonation process of the simulated concrete stainless steel system. The results show that the concrete has a strong ability to protect the internal stainless steel, and the stainless steel is not susceptible to local corrosion before the carbonation process of concrete is completed. In the early stage of the severe carbonation test, with the increase in immersion time, the capacitive semicircle diameter of the EIS plot is changed slightly. At the later stage of the severe carbonation test, the capacitive semicircle diameter decreases significantly, which indicates the damage and corrosion of passive film on the stainless steel surface. When the stainless steel remains passive, its corrosion potential is positive. However, the corrosion potential of stainless steel decreases rapidly when the corrosion process is being occurred. The morphology of the surface of specimens after the severe carbonation test shows that almost all metal surfaces of stainless steel in concrete are corroded after complete carbonation.
\end{abstract}

Keyword: 304 Stainless steel; Reinforced concrete; EIS; Corrosion.

\section{$\underline{\text { FULL TEXT }}$}

(C) 2021 The Authors. Published by ESG (www.electrochemsci.org). This article is an open access article distributed under the terms and conditions of the Creative Commons Attribution license (http://creativecommons.org/licenses/by/4.0/). 